\title{
PAIISES POBRES - PAÍSES RICOS: COMO SE DISTRIBUI A RENDA
}

\section{Dennis Cintra Leite*}

1. Introdução. 2. Os instrumentos. 3. Trabalho anterior. 4. A distribuicâo da renda no mundo para os anos de 1949, 1957, 1961, 1965 e 1967. 5. Resultados do computador. 6. Conclusóes.

\section{Introdução}

A preocupação pela maneira com que a renda é distribuída, entre os componentes de uma sociedade, é um tema que já vem interessando os economistas desde a época dos fisiocratas - a primeira escola de economistas pròpriamente dita. Na realidade, ricos $e$ pobres é uma temática que vem de períodos, em muito, antedatando o início da era cristã.

No entanto, só em época relativamente recente, ou seja, no século passado, é que um instrumental para medir-se objetivamente a distribuição de renda dentro de uma sociedade passa a existir. De fato, a primeira tentativa de medir a distribuição de renda coincide com a econometria e marca o seu início como ramo auxiliar da economia. Vilfredo Pareto (1848-1923) conduz a primeira investigação econométrica e descobre uma certa regularidade na distribuição da renda em um bom número de sociedades por êle investigadas. Estas sociedades variam no espaço, do "Peru às comunidades européias" 1 e variam no tempo de 1471 a $1894 .^{2}$ As investigaçōes de Pareto, na determinação desta regularida-

\footnotetext{
* Professor-assistente do Departamento de Economia da Escola de Administraça de Empresas de Scao Paulo, da Fundaçáo Getúlio Vargas.

1 Davis, $\mathbf{H}$. The theory of econometrics. Indiana, The Principia Press, 1941. p: 30.

2 ParbTo, Vilfredo. Cours d'économie politique. Genève, Libraire Droz, 1964.
}

R. Adm. Emp., Rio de Janeiro de de distribuição, por êle citada, nos fornece a primeira medida objetiva de distribuição de renda de que se tem notícia. ${ }^{3}$ Neste trabalho, nos propomos a empregar o instrumental desenvolvido por Pareto na determinação, não de como se distribui a renda dentro de uma sociedade em particular, mas sim como esta se distribui no mundo como um todo, não entre indivíduos, mas entre países. Para isto, usamos a renda per capita de cada país como representativa do habitante típico dêsse país. Reconhecemos, com isto, a violência que cometemos contra a realidade, dado que a distribuição interna nem sempre é homogênea. Mas como nosso objetivo é contrapor países ricos e países pobres, essa violência será desculpada. Para aquêles já familiarizados com as técnicas de determinação da distribuição de renda, recomendamos ir diretamente à seção seguinte do nosso artigo.

\section{Os instrumentos}

No eixo horizontal $(x)$ de duas coordenadas cartesianas, Pareto escalou a renda por família, enquanto que no eixo vertical $(y)$ escalou o número de famílias que tinham renda igual ou superior a $x$. Pareto mostrou que, em todos os casos por êle estudados, as curvas que representam a distribuição da renda ti-

3 LaNGe, Oskar. Introdução à econometria. Editôra Fundo de Cultura, 1961. p. 151.

$11(2): 74-85$

Abr./Jun. 1971 
nham o mesmo formato, isto é, hipérboles com a equação $\mathrm{y}=\mathrm{A} /(\mathrm{x}-\mathrm{a})^{\alpha}$, onde $a$ representa a menor renda onde começa a curva e A e $\alpha$ são parâmetros positivos.

A curva pode ser representada como na figura 1.

FIGURA 1

Número de unidodes familiares

com uma renda de $x$ ou mais.

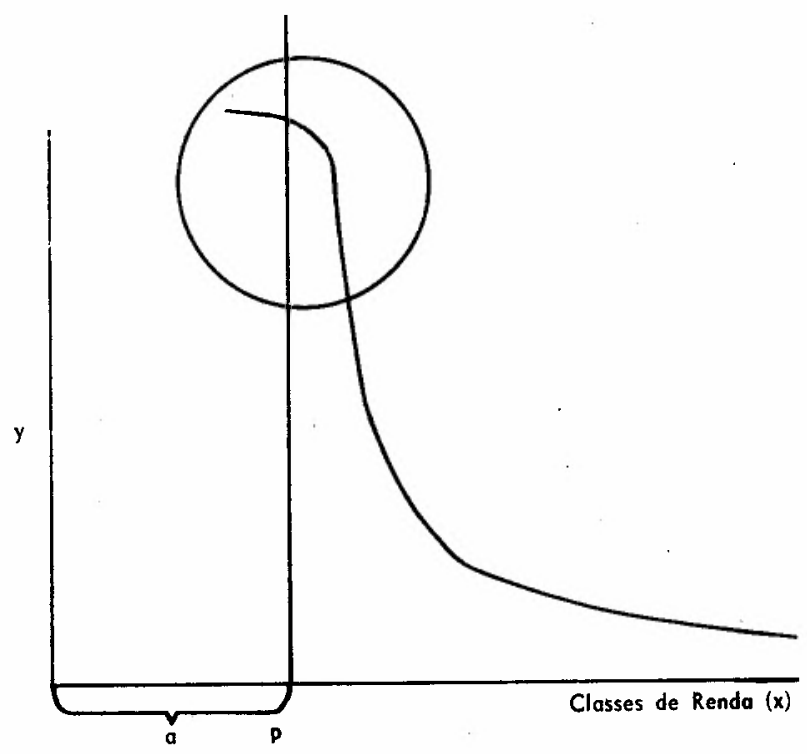

Pôsto que quando $\mathrm{x} \rightarrow \mathrm{a}, \mathrm{y} \rightarrow \infty$, e quando $\mathrm{x} \rightarrow \infty, \mathrm{y} \rightarrow 0$, a curva tem duas assíntotas $\mathrm{x}=\mathrm{a}$ e $\mathrm{y}=0$. Se deslocarmos o eixo $y$ ao ponto $p$ correspondente à menor renđa, então $\mathrm{a}=0$ e a distribuição de Pareto toma a forma:

$$
\mathrm{y}=\frac{\mathrm{A}}{\mathrm{x}^{\alpha}}
$$

Esta é, aliás, a expressão mais comum da distribuição de Pareto, pôsto que, a maior parte dos dados sôbre renda são extraídos de estatísticas de Impôsto de Renda, que omitem dados sôbre as rendas baixas. Se tivéssemos informações sôbre a população mais pobre veríamos que a curva cortaria o eixo $\mathrm{x}=\mathrm{a} \mathrm{em}$ algum ponto, onde a distribuição de Pareto deixaria de ter validade.
Podemos representar a distribuição pareteana em forma logarítmica, ou seja:

$\log \mathrm{y}=\log \mathrm{a}-\alpha \log \mathrm{x}$,

o que simplifica o processo de ajustamento da curva pelo método de mínimos quadrados. ${ }^{4}$ Esta apresentação logarítmica da distribuição também tem a vantagem de nos fornecer o parâmetro alfa, indicador da inclinação da reta em gráfico logaritmo em ambos os eixos. O parâmetro alfa indica a convexidade da hipérbole em referência à origem. Se alfa tender ao infinito a hipérbole é absorvida por sua assíntota vertical, o que indica que todos os componentes de uma sociedade têm aquela renda ( $a$ na figura 1) ou que, em gráfico duplamente logaritmo, a reta se torna vertical. No outro extremo, quando alfa tende a zero, a desigualdade na renda está se tornando maior, com a hipérbole se tornando mais convexa e mais próxima tanto do eixo $x$ como do eixo $y$ (isto é, um grande número de famílias com rendas muito baixas, e um ínfimo número de famílias com rendas muito altas) . Na representação logarítmica da distribuição a reta se aproxima do eixo $\log x$.

Ao calcular o parâmetro alfa, Pareto descobriu que êste variava de 1,13 em Augsburg em 1536, a 1,89 na Rússia em 1852 com uma média de 1,51.

Colin Clark coletou cálculos, tanto de Pareto como de outros investigadores, referentes a 153 diferentes observações em sociedades dispersas no espaço e no tempo e obteve como média 1,6841, com um desvio-padrão de 0,2798. Nas palavras de Pareto, “Ces résultats sont remarquables", ${ }^{5}$ pois mostram uma surpreendente estabilidade na distribuição da renda tanto dentro de qualquer sociedade individual como entre sociedades comparadas entre si.

De fato, supondo uma distribuição normal da variável alfa, sabemos que $99 \%$ das observações encontrar-se-ão dentro de três desvios-padrões da média, ou seja entre 0,8447 e 2,5235.

4 Johnson, N. O. The Pareto Law. Review of Economic Statistics, 19, 1937.

- Pareto. Cours, p. 312 
Lorenz teceu uma crítica à abordagem de Pareto. De fato, diz êle: "O método (de $\mathrm{Pa}$ reto) é especialmente inaplicável a dados onde o intervalo mais alto é dado como aquêles recebendo mais que uma dada quantia, pois, imagine uma comunidade onde o indivíduo mais rico se torna multimilionário sem nenhuma mudança na riqueza dos outros (componentes da sociedade). A curva de Pareto nada nos mostraria acêrca desta modificação". ${ }^{6}$

Lorenz propôs que se lançasse, ao longo de um eixo, o percentual acumulado da população. A curva resultante representaria a distribuição relativa da renda, com uma distribuição perfeitamente igualitária representada por uma reta de 450 relativa à origem. $\mathrm{Na}$ opinião de Lorenz, esta representação resolveria a limitação da distribuição de Pareto, embora só tivesse um significado visual, pois nenhuma medida quantitativa foi associada a ela.

Ficou para Gini $^{7}$ sugerir uma medida quantitativa, que, associada à distribuição de Lorenz, nos daria um índice de desigualdade na distribuição.

Representamos abaixo, na figura 2, a curva de Lorenz tal que fique mais claro o significado da medida sugerida por Gini.

FIGURA 2

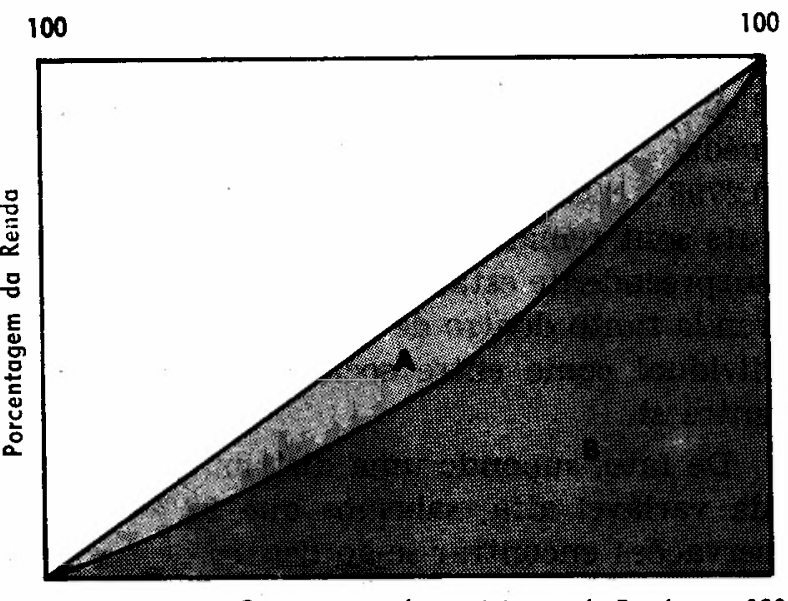

Porcentagem dos recipientes de Renda 100

- LORENz, M. $O$. Methods of measuring the concentration on wealth. Publications of the American statistical Association, 9, N.s.: 209-19, 1905.

7 Davis. Theory. p. 34.
Gini sugeriu que se dividisse a área $A$ pela área $A+B$ e chamar de $\varrho=\frac{\text { área } \mathrm{A}}{\text { área }(\mathrm{A}+\mathrm{B})}$ o "índice de concentração".

Esta medida é útil pôsto que sua contrapartida visual tem muito mais conteúdo intuitivo do que o coeficiente de Pareto.

No entanto, surpreendentemente, verificamos que estas duas medidas: especificamente, o coeficiente de Pareto e o índice de concentração de Gini podem ser derivados um do outro. Davis' ${ }^{8}$ nos apresenta esta dedução, a qual pouparemos ao leitor. Pode-se mostrar que na formulação básica, onde o é o índice de concentração de Gini, $\alpha$ é o coeficiente de Pareto.

$$
\varrho=\frac{1}{2 \alpha-1}
$$

Isto nos fornece um método simples de converter o coeficiente de Pareto no índice de concentração de Gini; sempre que tendo um desejamos o outro. Um aviso: como pode fàcilmente ser observado, se $\alpha$ é menor que 1 , a relação deixa de ter sentido, somos novamente forçados a lançar mão do método tradicional de mínimos quadrados para achar o coeficiente de Pareto. Se $\varrho=\frac{1}{2 \alpha-1}$ e se $\alpha<1$, o índice de concentração é maior que 1 , o que é fàcilmente verificável ser impossível.

Outra medida de distribuição de renda que se provou útil é o desvio-padrão absoluto que consiste de:

$$
\rho=\sqrt{\frac{\sum F_{i}\left(X_{i}-M\right)^{2}}{M}}
$$

onde:

$$
\begin{aligned}
& \mathbf{F}_{\mathbf{i}}=\text { Frequiência da observação } \\
& \mathbf{X}_{\mathbf{1}}=\text { Valor da observação } \\
& \mathbf{M}=\mathbf{M e ́ d i a ~ d a ~ d i s t r i b u i c ̧ a ̃ o ~} \\
& \mathbf{m}=\mathbf{\Sigma} \mathbf{F}_{\mathbf{i}}
\end{aligned}
$$$$
\text { s Ibld., p. 33-4. }
$$ 
Este pode ser convertido para um desviopadrão relativo, isto é, o desvio-padrão dividido pela média. $\mathrm{H}$. Dalton ${ }^{\circ}$ tentou algumas dessas medidas no que diz respeito ao principio de transferência, onde uma medida de distribuição de renda deve mostrar uma melhoria quando há uma transferência de um recebedor de renda alta para um recebedor de renda baixa. Sob êste teste, tanto o desviopadrão absoluto como o relativo provam ser boas medidas. O coeficiente de Pareto pôsto que é tomado como uma lei empírica, "não permite julgamento". Dalton também não testa o índice de concentração de Gini percebendo a íntima ligação entre a medida pareteana e de Gini.

\section{Trabalho anterior}

De nosso conhecimento as únicas tentativas feitas a título de comparação da distribuição da renda no mundo como um todo através do cômputo da distribuição de Pareto foram feitas por $H$. Theil e por L. J. Zimmerman. ${ }^{10}$ Theil coletou dados acêrca da renda per capita das Nações Unidas de 1949 e calculou o coeficiente de Pareto baseado nestas estatísticas; Zimmerman, por outro lado, coletou a renda per capita, a preços de 1953, referentes a 56 países para o ano de $1860,1880,1900$, 1913, 1929, 1953 e 1959. Reuniu êstes dados de maneira a poder comparar a distribuição da renda no mundo nesses anos, trazendo à superfície quaisquer tendências consistentes que se pudessem verificar.

Inicialmente dividiu o mundo em 12 áreas geoeconômicas :

\footnotetext{
9 Dalton, $\mathbf{H}$. The measurement of the inequality of income. Economic Journal, 30: 348-61, 1920.

10 THEIL, H. Entge Kwantitatieve aspecten van het probleen der hulpverlentng aun onderont1-wikkelde Landur. $D e$ Economist, 1953, 72-149 p. In: ZIMMERMAN, Louis Jacques. The distribution of world income 1860-1960. Essays on unbalanced growth. Ed. Egbert de Vries, Graventrage, Mouton \& Co., |n.d.| p. 28-55; ver também ZIMMmranas. Poor lands, rich lands: the widening gap. New York, Random House, 1965.
}

Abril/Junho 1971
1. América do Norte

2. Oceânia

3. Noroeste Europeu

4. União Soviética

5. Europa Sul Oriental

6. América Latina

7. Japão

8. Oriente Médio

9. Oriente

10. Asia Central

11. Ásia Sul Oriental

12. China

Diz que esta divisão foi feita para eliminar quaisquer flutuações a curto prazo que pudessem influir nos resultados de qualquer área em particular. ${ }^{11}$ Embora Zimmerman não o mencione, parece-nos que a razão mais relevante para êste agrupamento é o fato de que para todo período, exceto os dois últimos anos, especìficamente, 1953 e 1959, os dados pertinentes estão faltando para uma boa parte dos países de cada área. Embora seja frisado, não é uma razão suficiente para criticar o autor, pôsto que os dados para a maior parte do mundo, simplesmente não existem para os anos que êle se propõe investigar. Mas pelo agrupamento em áreas, se tornou possível a Zimmerman fornecer uma renda total para cada área como um todo. Disto, êle pode apresentar-nos um dado, aparentemente mais preciso, de renda per capita desta área. Parece-nos que o mesmo resultado poderia ser conseguido por via mais direta, pela simples estimativa razoável da renda per capita de cada país na amostra, e assim a necessidade de agrupá-los em áreas geoeconômicas poderia ser dispensada. Seu argumento, de que tal tipo de agrupamento serve para minimizar as flutuações a curto prazo nos dados de renda, simplesmente não nos convence como critério válido. Visto que o objetivo é comparar flutuações a longo prazo na distribuição da renda no mundo, aquilo que acontece com cada país individual no perfil é irrelevante. Agrupá-lo de uma maneira ou de outra em nada afetará a distribuição como um todo.

Os dados usados por Zimmerman como sendo a renda total de uma área, onde os

11 ZIMmRrman. Distribution, p. 30. 
componentes individuais não constam, não são explicados. Supomos que o autor usou estimativas razoáveis para essas rendas totais, mas não conseguimos determinar quais foram os critérios por êle usados. Por exemplo, no ano de 1870 , êle não tem dados individuais para os países da América Latina, embora use US\$ $\$ 3,7$ bilhões (dólares de 1953) como o total para a área. Na tabela de renda per capita inexplicàvelmente encontramos a Jamaica como tendo uma renda per capita de US\$ 80,00 , enquanto a renda per capita média para América Latina é conveniente: US\$100,00. Parece-nos razoável que, se êle sabia a renda per capita da Jamaica junto com sua população (que menciona em sua tabela referente à população dos respectivos países em cada data por êle estudada), seria fácil computar a renda global da ilha. Embora o fato acima não seja de primordial importância, nos leva a uma impressão de falta de cuidado na apresentação de seus resultados.

O próximo passo dado por Zimmerman é o cálculo do coeficiente de Pareto para os seguintes anos:

$\begin{array}{cc}\text { Ano } & \text { Coeficiente de Pareto } \\ 1860 & 1,576 \\ 1900 & 1,086 \\ 1929 & 0,911 \\ 1959 & 0,708 \\ \text { Ano } & \text { Coeficiente de Pareto } \\ 1880 & 1,086 \\ 1913 & 0,974 \\ 1953 & 0,767\end{array}$

H. Theil, ao fazer o mesmo cálculo para o ano de 1949 obteve um coeficiente de Pareto de $\mathbf{0 , 6 6 0}$. Abaixo damos nossos próprios cálculos do alfa de Pareto. O método por nós usado será visto na próxima seção.

$\begin{array}{ll}1949 & 0,761 \\ 1957 & 0,786 \\ 1961 & 0,759 \\ 1965 & 0,747 \\ 1967 & 0,726\end{array}$

Nossos cálculos para o ano de 1949 $(0,761)$ e o de Zimmerman para o ano de $1963(0,767)$ estão bastante próximos, mas ambos distantes do cálculo de Theil que indica 0,660 para o primeiro ano. Tendemos a acreditar que os nossos dados, junto com os de Zimmerman, tenderiam a confirmar uns aos outros em contraposição a Theil.

Embora a diferença não seja substancial, tendemos a duvidar da súbita queda a 0,708 em 1952 pelos cálculos de Zimmerman. Observamos uma piora de $8 \%$ na situação em um período de seis anos. Não há razão $a$ priori para isto, e acreditamos que nossos próprios cálculos são mais representativos da situação verdadeira.

Zimmerman segue dando-nos a distribuição percentual da renda em contraposição à população em cada um dos anos de seu estudo, confirmando, com isto, uma deterioração da distribuição de renda no mundo tendo como início o ano de 1860 até o presente.

Embora Zimmerman faça uma defesa razoável de sua tese de que tem havido uma deterioração marcante na distribuição mundial da renda, sentimos que seus dados contêm omissões das mais graves principalmente nos anos mais distantes: o Sudeste Europeu, a América Latina, o Extremo Oriente, e a total omissão em todo o estudo do Oriente Médio e da Africa, o que exclui uma boa parte da população mundial. Não há razão para que não tivesse incluído estas duas últimas regiōes no estudo nos anos mais recentes, onde os dados são razoàvelmente acessíveis.

Os coeficientes de Pareto de Zimmerman estão razoàvelmente de acôrdo com os nossos em um dos anos, o ano que usa como base para suas comparações de preços. Preocupamo-nos com a possibilidade de que isto não passe de uma mera coincidência com distorções significativas nos outros anos, como já, de fato, percebemos no ano de 1959 .

De qualquer maneira, parece-nos que Zimmerman levantou uma questão que merece a maior preocupação quando mostrou a evolu- 
ção da distribuição da renda no mundo no último século.

4. A distribuição da renda no mundo para os anos de 1949, 1957, 1961, 1965 e 1967.

Com a ajuda de dados levantados em companhia do Professor Wiliam Thweatt, ${ }^{12}$ fomos capazes de representar a renda per capita de pràticamente todos os países do mundo em uma função crescente da renda, variando dos mais pobres aos mais ricos.

Em contraposição a Zimmerman, achamos mais útil representar os dados não subdivididos por regiōes do mundo, que para nós nada significava, mas sim divididos os países em têrmos de renda per capita. Visto que estamos interessados na observação da distribuição da renđa e não na distribuição geográfica, esta abordagem nos permite um instrumental mais útil quando compararmos os parâmetros de distribuição.

Entre nossos objetivos, intencionamos mostrar como a distribuição da renda se tem comportado nos anos depois de 1949. Escolhemos êsse ano como nosso ponto de partida por duas razões: primeiro, achamos que os dados reportados pela ONU de maneira consistente tendiam a dar-nos uma idéia melhor da distribuição da renda nos anos após-guerra do que quaisquer dados que poderíamos obter para anos anteriores. Em segundo lugar, pareceu-nos que um período de 18 anos, aquêle coberto por nosso estudo, é período suficientemente longo para que se manifestassem quaisquer tendências inerentes às variáveis.

Um segundo objetivo é a determinação de como a renda se tem comportado nas pontas da distribuição, isto é, como a renda se con-

\footnotetext{
12 O Professor Wiliam Thweatt da Universidade de Vanderbil nos colocou à disposição algumas interpolaçós que fêz nos dados que usamos. Os dados de 1949 vieram de Statistical office of the United Nations national per capita incomes: seventy countries - 1949 (New York, United Nations, 1950), com as lacunas referentes à Africa e à Ásia Interpoladas pelo Prof. Thweatt; os dados de 1957 foram retirados de Usur, Mikoto \& HAGEN, F. F. World income, 1957. Cambridge Center for Intermational Studies, MIT, 1959, tamberm com as lacunas supridas pelo Prof. Thweatt; os dados de 1961 vieram de ROSENSTEIN-RODAN, P. N. International aid for underdeveloped countries. The Review of Economics and Statistics, 43 (2): 106-38, maio 1961; os dados relativos a 1965 e
}

centrou nos dois extremos da distribuição de renda, entre os muito ricos e os muito pobres.

Isto, imediatamente, nos leva à questão da definição da pobreza e da riqueza no mundo. Por analogia com estudos de pobreza dentro de uma economia ${ }^{13}$ podemos perceber que "duas abordàgens têm sido usadas para o eśtabelecimento de pontos-limite (i.e. onde começa a pobreza) : o critério absoluto e o critério relativo. Os absolutistas procuram algum ponto definitivo na escala de renda para a distinção entre níveis de renda, os relativistas preferem algum percentual ou proporção do campo de variação para diferenciar os padrões de vida". ${ }^{14}$ Os absolutistas preferem um nível divisório preciso, mas parece haver alguma controvérsia acêrca de onde se encontra êste nível. Os relativistas, aliás, também lutam com definições contraditórlas quanto ao ponto divisório.

Não investigaremos mais a fundo a controvérsia, principalmente no que diz respeito an nível divisório, isto é, onde ou em que nível de renda começa a pobreza, pois os limites sugeridos se referem à distribuição de renda dentro de uma economia, e nós estamos interessados em como a renda é distribuída no mundo como um todo. Nosso objetivo em chamar atenção à controvérsia é dar o pano de fundo para nossa própria escolha da definição de pobreza.

Preferimos aderir ao ponto de vista dos relativistas. Isto por diversas razões; a primeira das quais é que estamos lidando com uma série de anos, onde modificações no nível geral de preços se torna relevante, e não desejamos um contínuo ajuste do ponto divisório, implícito em uma definição absoluta de pobreza. Também reconhecemos que, mesmo quando falamos de países subdesenvolvidos 0 têrmo pobreza tem sido usado para definir "pessoas que através de circunstâncias permanentes ou temporárias peculiares a elas não têm à sua disposição, em uma forma ou

\footnotetext{
13 Task Force on Economic Growth and Opportunity. The concept of poverty, n.p., Chamber of Commerce of the United States, 1965; The problems of measuring poverty, The British Journal of Soctology, $\mathrm{V}, 18$ (1): 12, mar. 1967.
}

14 MENCHER. Poverty. p. 4-5. 
em outra, os meios de subsistência a um nível encontrado entre a maioria das pessoas vivendo na mesma cidade ou comunidade", ${ }^{15}$ o que é essencialmente um ponto de vista relativo.

Pensamos em usar alguma medida ordinal que melhor definiria o ponto-limite da pobreza e definir como alguma proporção ou percentil da renda mediana da população. No entanto, é possível demonstrar que a renda mediana do mundo é representada pela Tanzânia e consiste em US $\$ 80,00$ por pessoa ao ano. Isto, está claro, faz a mediana uma referência pouco propícia como ponto-limite da pobreza, pois representa a renda per capita mais baixa do mundo. No entanto, seguindo a sugestão do Prof. Thweatt, lançamos mão de uma medida que podemos chamar de renda ajustada pela média. Esta medida consiste, simplesmente, em tomar-se a renda per capita de qualquer país, individualmente, e dividi-la pela renda per capita média do mundo. A unidade de medida se torna renda média do mundo. A medida resultante consiste de múltiplos desta medida. Isto nos dá diretamente uma medida ordinal, e, mais importante, um indicador cardinal mas proporcional, do montante da renda per capita em um país $X$, em relação ao mundo como um todo.

A renda ajustada pela média tem mais uma vantagem, ou seja, não se torna mais necessário o ajuste ou redução de nossos dados sôbre a renda em dólares constantes de algum ano, arbitràriamente escolhido. Esta tentativa introduziria um problema de índice de preços a distorcer nossos dados. Deve ser lembrado que índice correto a ser usado deveria ser baseado no comércio internacional. De nosso conhecimento tal índice não existe. Seríamos forçados a lançar mão de um índice de custo de vida interno nos Estados Unidos, ou então de preços por atacado dêste mesmo país. Ambos caminhos introduziriam mais uma fonte de ruído em nossos cálculos.

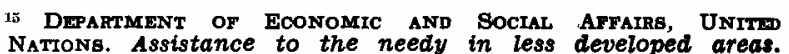
NATIONs. Assistance to the needy in less developed areas.
New York, U.N., 1965. In: MrNckgR. Measuring. f. 8.
O dado ajustado pela média também permitirá o cálculo dos coeficiente de Pareto, sem distorção introduzida pela inflação ou pelo crescimento igual da renda média do mundo sem qualquer melhora em sua distribuição.

Uma vez que os dados de renda per capita foram ajustados pela média, o problema de definir pobreza ainda permanecia sem solução. O que fizemos para o estabelecimento dêste limite foi dividir os países do mundo, tomando qualquer ano, em dez categorias de renda ajustada pela média. Dentro de cada uma destas categorias incluem-se todos os países que têm uma renda per capita ajustada pela média dentro dos limites de classe da seguinte maneira definidos:

$\begin{array}{lll}0-0,25 & 1,01-1,25 & 2,01-3,00 \\ 9,26-0,50 & 1,26-1,50 & 3,01-4,00 \\ 0,51-0,75 & 1,51-2,00 & 4,01 \text { e mais } \\ 0,76-1,00 & & \end{array}$

Pareceu-nos que qualquer país tendo menos que metade da renda per capita ajustada pela média poderia seguramente ser classificado como pobre. A metade inferior dêste grupo, especìficamente, aquêles com 0,25 ou menos da renda média do mundo seriam classificados como de extrema pobreza. Êste será o grupo a que nos estaremos referindo quando falarmos do hiato entre os ricos e os pobres. Os ricos, está claro, são aquêles que pertencem à categoria mais alta de nossa classificação, especìficamente, aquêles com quatro ou mais vêzes a renda média do mundo.

A divisão das categorias de renda em dez grupos tem a vantagem de permitir-nos o uso da técnica de regressão para a determinação do coeficiente de Pareto sem uma perda excessiva de graus de liberdade.

\section{Resultados do computador}

Escrevemos um programa de computador que, tendo como insumo os dados sôbre a população e a renda de cada país do mundo, determina a renda total do mundo, o PNB

Revista de Administração de Emprêsas 
mundial, a renda ajustada pela média de cada categoria, a percentagem da população mundial em cada categoria, a percentagem do PNB mundial em cada categoria. Também calcula o hiato absoluto em têrmos de renda entre os grupos de renda per capita altos e baixos (em nossa terminologia os extremamente pobres - RAM $^{16}=0,25$ menos $-\mathrm{e}$ os ricos $-\mathrm{RAM}=4,00$ ou mais). A razão entre os ricos e os extremamente pobres também é calculada. No próximo passo os quatro momentos da distribuição e os coeficientes Beta (assimetria e curtose), da mesma, junto com o desvio-padrão são gerados e impressos. Estes coeficientes são dados em têrmos das rendas ajustadas pela média e em têrmos de dólares. Isto nos permite uma comparação em perfil dentro da distribuição de um dado ano, através do uso tanto dos coeficientes ajustados pela média como em têrmos absolutos. Os coeficientes ajustados pela média, também nos permitem comparações intertemporais de ano para ano. ${ }^{17}$

Calculamos os coeficientes de Pareto nos anos de nosso estudo pelo uso do método dos mínimos quadrados com uma modificação: mostramos o logaritmo da população tendo uma certa renda, ou mais, no eixo vertical, mas no eixo horizontal, ao invés de categoria de renda em têrmos de dólares, usamos o logaritmo da renda per capita ajustada pela média. Isto nos permite lançar as curvas de Pareto de ano a ano e torná-las comparáveis tanto no eixo vertical como no horizontal quando lançadas no mesmo gráfico. Mostramos abaixo uma tabela contendo os principais coeficientes de distribuição para os anos do nosso estudo.

Especificamente, o coeficiente de Pareto, o coeficiente de Gini, o hiato entre os extremamente pobres e os ricos ajustado pela média, o desvio-padrão desta medida, o hiato absoluto, seu desvio-padrão e finalmente a razão entre os países mais ricos e os mais pobres.

\footnotetext{
4i nAм = Renda per Capita AJustada pela Média.
}

ii Ver apêndice.

$\begin{array}{cccc}\text { Ano } & \begin{array}{c}\text { Coeficiente } \\ \text { de Pareto }\end{array} & \text { Gini } & \begin{array}{c}\text { Hiato } \\ \text { Relativo }\end{array} \\ 1949 & 0,761 & 0,647 & 6,10 \\ 1957 & 0,786 & 0,633 & 5,92 \\ 1961 & 0,759 & 0,633 & 5,57 \\ 1965 & 0,747 & 0,644 & 5,69 \\ 1967 & 0,726 & 0,650 & 5,79 \\ & & & \\ & \text { Hiato } & \text { D.P. } & \text { Razão } \\ \text { D.P. } & \text { Absoluto } & & \text { Robres } \\ 1,58 & 1,555 & 404 & 36,94 \\ 1,54 & 2,449 & 635 & 34,7 \\ 1,47 & 2,644 & 698 & 33,8 \\ 1,48 & 3,154 & 822 & 37,6 \\ 1,71 & 3,535 & 920 & 40,12\end{array}$

Uma das primeiras coisas que nos chama a atenção nos cálculos acima é o fato de que, embora a tendência do hiato absoluto entre os grupos de renda alta e de renda baixa tenha sido a de deteriorar-se (isto é, tornar-se maior), à medida que se passaram os anos, o hiato relativo não tem repetido êsse comportamento. De fato, êste caiu de um ponto mais alto de 6,10 em 1949 a um baixo de 5,57 em 1961 e mostrou um pequeno incremento desde então. O hiato relativo, em nossa definição de pobreza, é uma medida mais útil que o hiato absoluto, como podemos constatar acima.

Chama-nos a atenção, também, o desacôrdo entre o índice de concentração de Gini e o coeficiente de Pareto no ano de $1961 \mathrm{com}$ parado com o ano de 1957 . O primeiro diz que a situação piorou enquanto o coeficiente de Gini nega essa tendência. A medida em que o ajustamento da curva de Pareto não é perfeita, tendemos a aceitar o diagnóstico do índice de concentração de Gini. Isto é confirmado quando constatamos que os outros coeficientes estão mais de acôrdo com a medida de Gini que com a de Pareto. Outra tendência que nos parece interessante é o fato de que o hiato ajustado pela média entre os países ricos e os pobres, junto com o desviopadrão da renda per capita ajustada pela média, são quase imagens perfeitas uma da 
outra. Isto é uma observação útil, pois nos mostra como o desvio-padrão ajustado pela média reflete o hiato relativo. $\mathrm{Na}$ medida $\mathrm{em}$ que o desvio-padrão é uma medida ponderada, levando em conta, no nosso caso, a população de cada categoria de renda. Ela é, de fato, um indice melhor de como o espalhamento em tôrno da média está agindo de período para período. A ênfase tradicional, entretanto, tem sido dada ao hiato entre os países ricos e pobres do mundo, fato êste, aliás, que se reflete no título do livro de Zimmerman, ${ }^{18}$ Paises ricos e paises pobres, o hiato que cresce. Esta ênfase tradicional é também refletida no primeiro parágrafo do relatório de Pearson para a Comissão de Desenvolvimento Internacional (Commission on International Development): "O crescente hiato entre os países desenvolvidos e em processo de desenvolvimento se tornou a questão central de nossa era." 19

\section{Conclusões}

Vamos agora considerar as conclusões gerais que podem ser extraídas de nossos cálculos. Podemos notar que:

1. Todos os nossos coeficientes mostram e estão de acôrdo que a distribuição da renda no mundo melhorou, por pouco que seja, nos anos de 1957 e 1961, em relação ao ano de 1949 .

2. Depois dêsses anos houve uma pequena deterioração. Alguns dos indicadores (Gini, Pareto, razão entre os países ricos e pobres) mostram uma deterioração substancial, tal que a situação presente se tornou pior que em 1949. Outros (o hiato ajustado pela média, $\in$ o desvio-padrão) mostram uma piora relativa em comparação com 1959 e 1961 mas não uma deterioração suficiente para voltar à situação ainda pior de 1949 .

1. Ver nota 10.

19 PEarson, Lester B. et al. Partners in development report of the Commission on International Development. New York Publishers, 1969.
3. Embora o coeficiente de Pareto deixe algo a ser desejado no que diz respeito a sua absoluta precisão na descrição da distribuição de renda no mundo, seu nível (variando entre 0,726 e 0,786) fornece-nos um dado comparativo a inserir na seguinte discussão, em que Davis tece uma hipótese quanto ao nível do coeficiente de concentração e, portanto, de coeficiente de Pareto:

" $\mathrm{E}$ bastante plausível... inferir de fontes históricas que a Revolução Francesa e a mais recente Revolução Russa foram ambas agravadas, senão causadas, por uma concentração exc€ssiva da riqueza e da renda. Igualmente as tendências socialistas do govêrno espanhol depois da queda da monarquia certamente baixaram muito o índice de concentração de sua norma pareteana (i.e. 1,5) . A Guerra Civil pode assim ter sido uma conseqüência desta perturbação. A Guerra Civil Americana foi, em boa parte, a conseqüência da questão da escravidão nos estados sulinos. A distribuição da propriedade de escravos nesta região era aproximadamente pareteana e portanto um grande distúrbio foi causado no índice de concentração quando os escravos foram libertados. Não deixa de ser razoável a suposição de que a demora na recuperação econômica do Sul, quando comparada ao Norte não se deveu tanto ao fato de que o Norte saiu-se vencedor como ao deslocamento dos parâmetros de concentração.

Aventaremos a hipótese-tentativa de que uma revolução é provável em qualquer economia onde 0 índice de concentração excede um certo valor crítico maior que 0,5 (isto é, um coeficiente de Pareto menor que 1,5) e uma guerra civil é provável em qualquer economia onde $o$ índice de concentração cai abaixo de um certo valor crítico menor que 0,5 (isto é, um coeficiente de Pareto acima de 1,5) . Como a massa do povo é afetada no primeiro instante, a revolução será rápida e irreversível. No segundo instante as classes econômicas superiores, numèricamente pequenas, mas poderosas em recursos, são afe- 
tadas. Portanto, a guerra civil demora para começar e será de longa duração e conseqüentemente necessita ser alcançada em boa parte por meios mercenários.

Quais são os limites críticos, não temos, no presente, meios de estimar. Nos Estados Unidos, se excluirmos o período da Primeira Guerra, o índice de concentração tem variado de aproximadamente 0,40 (isto é, um valor de Pareto de 1,75), aproximadamente 0,60 (i.é., um coeficiente de Pareto de 1,33) sem distúrbios políticos de monta. Portanto, podemos supor que êstes limites não são ainda politticamente perigosos."

E meridiana a constatação de que os limites que Davis tem como seguros para a distri- buição de renda dentro de um país são em muito excedidos pelos nossos resultados para o mundo como um todo. Corroborados pela perspectiva histórica de Zimmerman, vemos que o mundo está em um nível de concentração de renda altamente periculoso. O fato de que de um lado da escala, $6 \%$ da população recebe $36 \%$ da renda, e que do outro $53 \%$ da população só tem $9,6 \%$ da renda mundial já é indicativo de que a situação é explosiva. Nossos cálculos mostraram não ter havido nenhuma tendência definitiva para uma melhora da situação. Pelo contrário, se tomarmos os resultados de Zimmerman junto com os nossos, as perspectivas para o futuro parecem pouco alentadoras.

\section{APENDICE}

Situação no ano: 1949

População do mundo: $2.273 .797 \mathrm{mil}$

Renda bruta do mundo: 579,421 bilhões

Renda per capita média do mundo: 254,825 dólares.

\begin{tabular}{|c|c|c|c|c|c|}
\hline $\begin{array}{l}\text { Categorias de } \\
\text { renda ajustada } \\
\text { pela média } \\
\text { em dólares }\end{array}$ & $\begin{array}{c}\text { Renda } \\
\text { per } \\
\text { capita } \\
\text { em dólares }\end{array}$ & $\begin{array}{l}\text { População } \\
\text { da } \\
\text { categoria } \\
1.000\end{array}$ & $\begin{array}{c}\text { Percentagem } \\
\text { da } \\
\text { população } \\
\text { do mundo. }\end{array}$ & $\begin{array}{c}\text { Renda } \\
\text { da } \\
\text { categoria } \\
\text { em bilhöes }\end{array}$ & $\begin{array}{c}\text { Percentagem } \\
\text { da } \\
\text { renda } \\
\text { do mundo }\end{array}$ \\
\hline 170 & 43,272 & $1.241 .694,0$ & 54,609 & 53,731 & 9,273 \\
\hline 427 & 108,837 & $208.274,9$ & 9,160 & 22,668 & 3,912 \\
\hline 620 & 157,968 & $102.007,9$ & 4,486 & 16,114 & 2,781 \\
\hline 870 & 221,823 & $19.173,0$ & 0,843 & 4,253 & 0,734 \\
\hline 1,048 & 266,958 & $90.961,9$ & 4,000 & 24,283 & 4,191 \\
\hline 1,346 & 342,900 & $286.838,3$ & 12,615 & 98,357 & 16,975 \\
\hline 1,614 & 411,197 & $22.685,0$ & 0,998 & 9,328 & 1,610 \\
\hline 2,301 & 586,416 & $75.558,9$ & 3,323 & 44,309 & 7,647 \\
\hline 3,441 & 876,934 & $77.388,9$ & 3,404 & 67,865 & 11,713 \\
\hline 6,273 & 1. 598,458 & 149.214 .9 & 6,562 & 238,514 & 41,164 \\
\hline
\end{tabular}

Coeficientes per capita

Hiato absoluto em dólares: 1.555,186 dólares

Desvio-padrão da renda em dólares: 404,166 dólares

Coeficientes de Gini da distribuição da renda: 6470.

Coeficientes ajustados pela média

Razão entre as categorias de renda mais alta e mais baixa: 36,940

Hiato ajustado pela média: 6,103 rendas médias do mundo.

Estes são os momentos da distribuição
$\mathrm{M} 2=2,5156 \quad$ Desvio-padrão $=1,5861 \quad \mathrm{M} 3=9,8638 \quad$ M4 $=52,3015$
$\mathrm{~B} 1=2,47225$
$\mathrm{~B} 2=8,26506$.


Situação no ano: 1957

População do mundo: $2.789 .085,0 \mathrm{mil}$

Renda bruta do mundo: $1.153,818$ bilhões

Renda per capita médía do mundo: 413,690 dólares.

\begin{tabular}{|c|c|c|c|c|c|}
\hline $\begin{array}{l}\text { Categorias de } \\
\text { renda ajustada } \\
\text { pela média } \\
\text { em dólares }\end{array}$ & $\begin{array}{c}\text { Renda } \\
\text { per } \\
\text { capita } \\
\text { em dólares }\end{array}$ & $\begin{array}{c}\text { População } \\
\text { da } \\
\text { categoria } \\
1.000\end{array}$ & $\begin{array}{c}\text { Percentagem } \\
\text { da } \\
\text { população } \\
\text { do mundo }\end{array}$ & $\begin{array}{c}\text { Renda } \\
\text { da } \\
\text { categoria } \\
\text { em bilhões }\end{array}$ & $\begin{array}{c}\text { Percentagem } \\
\text { da } \\
\text { renda } \\
\text { do mundo }\end{array}$ \\
\hline 175 & 72,581 & $1.388 .757,0$ & 49,793 & 100,798 & 8,736 \\
\hline 346 & 143,051 & $256.256,9$ & 9,188 & 36,658 & 3,177 \\
\hline $66 i$ & 276,023 & $310.299,6$ & 11,125 & 85,650 & 7,423 \\
\hline 883 & 365,233 & $71.056,0$ & 2,548 & 25,952 & 2,249 \\
\hline 1,192 & 493,035 & $116.880,0$ & 4,191 & 57,626 & 4,994 \\
\hline 1,449 & 599,558 & $222.064,9$ & 7,962 & 133,141 & 11,539 \\
\hline 1,668 & 690,027 & $32.790,0$ & 1,176 & 22,626 & 1,961 \\
\hline 2,473 & $1.023,253$ & $177.430,9$ & 6,362 & 181,557 & 15,735 \\
\hline 3,286 & $1.359,392$ & $24.700,0$ & 0,886 & 33,577 & 2,910 \\
\hline 6,096 & $2.521,762$ & $188.850,0$ & 6,771 & 476,235 & 41,275 \\
\hline
\end{tabular}

Coeficientes per capita

Hiato absoluto em dólares: 2.449,181 dólares

Desvio-padrão da renda em dólares: 643,986 dólares

Coeficientes de Gini da distribuição da renda: 6329.

Coeficientes ajustados pela média

Razão entre as categorias de renda mais alta e mais baixa: 34,744

Hiato ajustado pela média: 5,920 rendas médias do mundo.

\begin{tabular}{ll}
\hline & Estes são os momentos da distribuição \\
$\mathrm{M} 2=2,3560$ & Desvio-padrão $=1,5349 \quad \mathrm{M} 3=8,9709$ \\
$\mathrm{~B} 1=2,48067$ & $\mathrm{~B} 2=8,36846$.
\end{tabular}

Situação no ano: 1961

População do mundo: $3.074 .571,0 \mathrm{mil}$

Renda bruta do mundo: $1.459,917$ bilhões

Renda per capita média do mundo: 474,836 dólares.

\begin{tabular}{|c|c|c|c|c|c|}
\hline $\begin{array}{l}\text { Categorias de } \\
\text { renda ajustada } \\
\text { pela média } \\
\text { em dólares }\end{array}$ & $\begin{array}{c}\text { Renda } \\
\text { per } \\
\text { capita } \\
\text { em dólares }\end{array}$ & $\begin{array}{c}\text { População } \\
\text { da } \\
\text { categoria } \\
1.000\end{array}$ & $\begin{array}{c}\text { Percentagem } \\
\text { da } \\
\text { população } \\
\text { do mundo }\end{array}$ & $\begin{array}{c}\text { Renda } \\
\text { da } \\
\text { categoria } \\
\text { em bilhões }\end{array}$ & $\begin{array}{c}\text { Percentagem } \\
\text { da } \\
\text { renda } \\
\text { do mundo }\end{array}$ \\
\hline 170 & 80,541 & $1.655 .528,0$ & 53,846 & 133,338 & 9,133 \\
\hline 354 & 168,197 & $209.732,9$ & 6,822 & 35,276 & 2,416 \\
\hline 604 & 287,001 & $172.608,9$ & 5,614 & 49,539 & 3,393 \\
\hline 814 & 386,726 & $158.730,0$ & 5,163 & 61,385 & 4,205 \\
\hline 1,113 & 528,558 & $48.655,0$ & 1,582 & 25,717 & 1,762 \\
\hline 1,376 & 653,155 & $101.590,0$ & 3,304 & 66,354 & 4,545 \\
\hline 1,758 & 834,974 & $309.289,2$ & 10,060 & 258,248 & 17,689 \\
\hline 2,588 & $1.229,015$ & $180.000,0$ & 5,854 & 221,223 & 15,153 \\
\hline 3,309 & $1.571,365$ & $35.417,0$ & 1,152 & 55,653 & 3,812 \\
\hline 5,738 & $2.724,775$ & $203.020,0$ & 6,603 & 553,184 & 37,891 \\
\hline
\end{tabular}

Coeficientes per capita

Hiato absoluto em dólares: 2.644,234 dólares

Desvio-padrão da renda em dólares: 698,620 dólares

Coeficientes de Gini da distribuição da renda: 6333 .

Coeficientes ajustados pela média

Razão entre as categorias de renda mais alta e mais baixa: 33,831

Hiato ajustado pela média: 5,569 rendas médias do mundo.

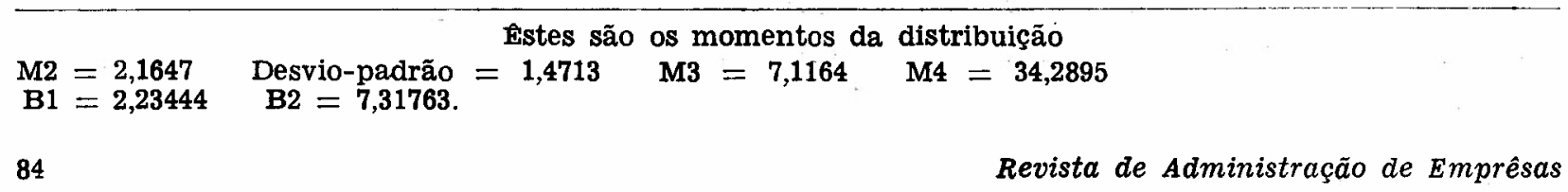


População do mundo: $3.286 .994,0$ mil

Renda bruta do mundo: $1.820,956$ bilhões

Renda per capita média do mundo: 553,988 dólares.

\begin{tabular}{cccccc}
\hline $\begin{array}{c}\text { Categorias de } \\
\text { renda ajustada } \\
\text { pela média } \\
\text { em dólares }\end{array}$ & $\begin{array}{c}\text { Renda } \\
\text { per } \\
\text { capita } \\
\text { em dólares }\end{array}$ & $\begin{array}{c}\text { População } \\
\text { da } \\
\text { categoria } \\
1.000\end{array}$ & $\begin{array}{c}\text { Percentagem } \\
\text { da } \\
\text { população } \\
\text { do mundo }\end{array}$ & $\begin{array}{c}\text { Renda } \\
\text { da } \\
\text { categoria } \\
\text { em bilhöes }\end{array}$ & $\begin{array}{c}\text { Percentagem } \\
\text { da } \\
\text { renda } \\
\text { do mundo }\end{array}$ \\
\hline 155 & 86,127 & $1,770.976,0$ & 53,878 & 152,529 & 8,376 \\
567 & 203,337 & $365.057,2$ & 11,106 & 74,230 & 4,076 \\
596 & 329,976 & $41.608,9$ & 1,266 & 13,730 & 0,754 \\
1,058 & 462,722 & $132.411,8$ & 4,028 & 61,270 & 3,365 \\
1,391 & 586,247 & $41.723,0$ & 1,269 & 24,460 & 1.343 \\
1,781 & 770,731 & $163.402,9$ & 4,971 & 125,940 & 6,916 \\
2,793 & 986,676 & $316.679,1$ & 9,634 & 312,459 & 17,159 \\
3,626 & $1.547,129$ & $212.431,9$ & 6,463 & 328,659 & 5,049 \\
5,849 & $2.008,517$ & $47.657,0$ & 1,450 & 95,720 & 5,257 \\
\hline
\end{tabular}

Coeflclentes per capita

Hiato absoluto em dólares: $3.153,912$ dólares

Desvio-padrão da renda em dólares: 821,881 dólares

Coeficientes de Ginl da distribuição da renda: 6443 .

Coeficientes ajustados pela média

Razão entre as categorias de renda mais alta e mais baixa: 37,619

Hiato ajustado pela média: 5,693 rendas médias do mundo.

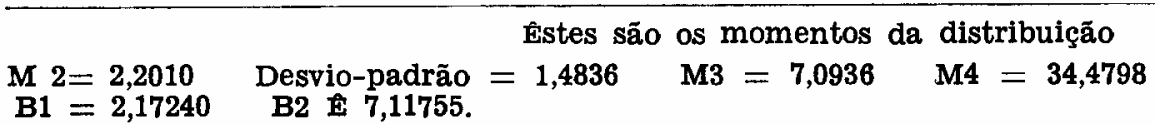

Situação no ano: 1967

População do mundo: $3.422 .285,0$ mil

Renda bruta do mundo: $2.090,470$ bilhōes

Renda per capita média do mundo: 610,840 dólares.

\begin{tabular}{|c|c|c|c|c|c|}
\hline $\begin{array}{l}\text { Categorias de } \\
\text { renda ajustada } \\
\text { pela média } \\
\text { em dólares }\end{array}$ & $\begin{array}{c}\text { Renda } \\
\text { per } \\
\text { capita } \\
\text { em dólares }\end{array}$ & $\begin{array}{c}\text { População } \\
\text { da } \\
\text { categoria } \\
1.000\end{array}$ & $\begin{array}{c}\text { Percentagem } \\
\text { da } \\
\text { população } \\
\text { do mundo }\end{array}$ & $\begin{array}{c}\text { Renda } \\
\text { da } \\
\text { categoria } \\
\text { em bilhöes }\end{array}$ & $\begin{array}{c}\text { Percentagem } \\
\text { da } \\
\text { renda } \\
\text { do mundo }\end{array}$ \\
\hline 148 & 90,354 & $1.809 .554,0$ & 52,876 & 163,500 & 7,821 \\
\hline 370 & 226,198 & $419.717,4$ & 12,264 & 94,939 & 4,542 \\
\hline 589 & 359,847 & $50.362,9$ & 1,472 & 18,123 & 0,867 \\
\hline 850 & 519,301 & $106.702,9$ & 3,118 & 55,411 & 2,651 \\
\hline 1,132 & 691,718 & $74.022,9$ & 2,163 & 51,203 & 2,449 \\
\hline 1,339 & 817,841 & $79.479,9$ & 2,322 & 65,002 & 3,109 \\
\hline 1,651 & $1.008,346$ & $415.290,6$ & 12,135 & 418,756 & 20,032 \\
\hline 2,722 & $1.662,509$ & $159.628,9$ & 4,664 & 265,384 & 12,695 \\
\hline 3,369 & $2.057,740$ & $99.944,9$ & 2,920 & 205,661 & 9,838 \\
\hline 5,935 & $3.625,052$ & $207.580,9$ & 6,066 & 752,491 & 35,996 \\
\hline
\end{tabular}

Coeficientes per capita

Hiato absoluto em dólares: $3.534,698$ dólares

Desvio-padrão da renda em dólares: 920,163 dólares

Coeficientes de Gini da distribuição da renda: 6495

Coeficientes ajustados pela média

Razão entre as categorias de renda mais alta e mais baixa: 40,121

Hiato ajustado pela média: 5,787 rendas médias do mundo.

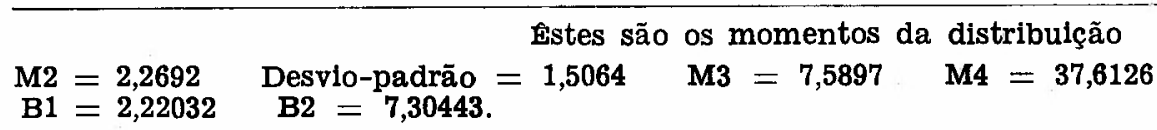

